\title{
Utilização de drogas veterinárias, agrotóxicos e afins em ambientes hídricos: demandas, regulamentação e considerações sobre riscos à saúde humana e ambiental
}

\author{
U se of veterinary drugs and pesticides in the aquatic \\ environment: demands, regulation and concerns \\ on risks to human and enviromental health
}

\author{
Adriana de Araújo Maximiano 1 \\ Renata Oliveira de Fernandes 1 \\ Flávio Pereira Nunes 2 \\ $M$ arcelo Prudente de Assis 3 \\ Ruben Vieira de M atos 4 \\ Cynthia Gonçalves Silva Barbosa 5 \\ Eduardo Cyrino Oliveira-Filho 6
}

\footnotetext{
1 Instituto Brasileiro do M eio Ambiente e dos Recursos $\mathrm{N}$ aturais Renováveis/DILIQ. SCEN - Trecho 2. Av. L 4 Norte, Edifício Sede Bloco C, 70800-200, Brasília DF. adriana.maximiano@ibama. gov.br

2 M inistério da Saúde, Secretaria de Vigilância em Saúde.

3 M inistério do M eio Ambiente, Secretaria de Qualidade Ambiental. 4 Centro Universitário de Brasília - UniCEUB, Faculdade de Ciências da Saúde.

5 Agência N acional de Vigilância Sanitária, GGTPS.

6 Embrapa Cerrados, Laboratório de Ecotoxicologia.
}

Abstract Chemical and biological products have been intentionally introduced into water bodies as aquatic plant herbicides, algicides, molluscicides, larvicides, fungicides and veterinary drugs. In Brazil these activities are regulated by different governmental agencies, which creates certain difficulties related to their control and management. This overview was conducted to evaluate the necessity of use and the Brazilian federal legislation related to this class of products, as well as to demonstrate the main origins of these demands and the legislative problems which often underestimate the risks of their uses to human and environmental health.

Key words Herbicides, Algi cides, Vector control, Aquaculture, Aquatic weeds
Resumo Vários produtos químicos e biológicos tais como: herbicidas, algicidas, moluscicidas, larvicidas, fungi cidas e drogas veterinárias têm sido intencionalmente introduzi dos nos ambientes hídricos. No Brasil estas atividades são reguladas por diferentes órgãos governamentais, o que gera dificuldades no controle e no gerenciamento. Este trabalho foi realizado com o objetivo de identificar as demandas nacionais para uso desses produtos e as lacunas existentes na legi slação federal pertinente que, muitas vezes, não estimam o risco oferecido por tais atividades para a saúde humana e ambiental.

Palavras-chave Herbicidas, Algicidas, Controle de vetores, A qüicultura, Plantas aquáticas 


\section{Introdução}

A água é um dos recursos naturais mais importantes para a vida, apresentando usos intensivos e diversificados. Além de ser componente vital no sistema de sustentação da vida na Terra, também é necessária para dar continuidade ao crescimento econômico das sociedades. Dentre os vários usos, destacam-se o consumo humano, a dessedentação de animais, a irrigação, o cultivo de espécies aquáticas, os processos industriais, a geração de energia, o lazer e a navegação ( $M$ aciel Jr. et al., 2000). Esses usos dependem dos padrões de qualidade da água dos recursos hídricos, os quais são estabelecidos por normas federais e estaduais.

No Brasil, a situação de poluição dos recursos hídricos apresenta-se de forma bastante diversificada, reflexo da variabilidade de desenvolvimento socioeconômico e disponibilidade hídrica nas regiões (Zampieron \& Vieira, 2003).

A falta de informação sobre a biodiversidade dos ecossistemas aquáticos no Brasil impede a sistematização de dados abrangentes, o que prejudica o desenvolvimento de políticas e planejamentos de ação para os recursos hídricos (Buss, 2002). Este cenário dificulta o estabelecimento de causa e efeito dos impactos da utilização de produtos químicos ou biológicos sobre os ambientes hídricos.

A adição, por quaisquer processos (despejo, lançamento, transporte, deriva ou lixiviação) não-intencionais, de substâncias químicas ou material biológico ao meio ambiente representa um impacto. M uitos desses processos podem implicar a eutrofização dos ambientes hídricos, mortandade de organismos aquáticos, ruptura de cadeias tróficas, e comprometimento ou inviabilização dos fins determinados para utilização da água.

Além de lançar resíduos de maneira direta ou indireta nos ambientes hídricos, o homem também vem interferindo nesses ecossistemas, por meio da aplicação direta de produtos agrotóxicos e afins, entre outras substâncias, com 0 objetivo de controlar espécies nocivas ou proteger espécies úteis, de acordo com seus interesses e necessidades.

N esse contexto, surge a preocupação sobre os possíveis riscos decorrentes da adição intencional (aplicação) desses produtos aos ambientes hídricos, com a finalidade de atender demandas planejadas e administradas pelos setores da saúde, agricultura, saneamento, energia, entre outros.
Assim sendo, o presente trabal ho tem como objetivo apresentar as demandas nacionais para a utilização de produtos nos diversos ambientes hídricos e as bases legais que disciplinam tais atividades, de modo a identificar as lacunas existentes no gerenciamento dessas ações.

\section{Demandas para uso de produtos em ambientes hídricos}

\section{Controle sanitário e de doenças em aqüicultura}

A aqüicultura é o ramo da zootecnia que trata do cultivo dos organismos que têm na água seu principal ou mais freqüente ambiente de vida. A piscicultura, em particular, apresenta um enorme potencial de crescimento no Brasil, devido a características como condições climáticas adequadas, grande rede hídrica e grande área coberta por reservatórios (Zaniboni Filho, 1997). Porém, o aproveitamento racional e otimizado desse potencial é ainda incipiente, causando problemas de ordem técnica e ambiental (Queiroz et al., 2002).

0 confinamento dos peixes em tanques, com alta densidade populacional, e a introdução de espécies exóticas, sem os cuidados sanitários necessários, criam condições que favorecem a introdução e o desenvolvimento de patógenos e parasitas. Para prevenir e controlar os danos decorrentes, os criadores têm utilizado produtos químicos, de forma indiscriminada. Como, de um modo geral, na aqüicultura a água é retirada de cursos d'água e devolvida a eles depois de passar pelos tanques, tais produtos podem ser transportados e causar impactos diversos em outros ambientes.

Entre os principais produtos utilizados em todo o mundo para o controle sanitário e de doenças em aqüicultura, destacam-se: cloreto de sódio, permanganato de potássio, azul de metileno, formaldeído, verde malaquita, sulfato de cobre, triclorfon, e os antibióticos, tetraciclina, eritromicina e a oxitetraciclina.

\section{Controle de algas}

As al gas azuis (cianobactérias ou cianofíceas) são microrganismos componentes do fitoplâncton em ambientes dulcícolas. Algumas espécies desse grupo produzem toxinas que ao serem liberadas para a água podem ocasionar efeitos tóxicos no ser humano e em outros or- 
ganismos habitantes do meio. Fatores como a eutrofização dos ambientes hídricos, ocasionada principalmente pelo lançamento de nutrientes na água (ex.: esgoto, fertilizantes), aumentam de forma excessiva a população dessas al gas e dão origem ao fenômeno chamado floração ou bloom (Sant'Anna \& Azevedo, 2000). Desse modo, surge a necessidade do controlee do monitoramento dessas populações nas represas destinadas ao abastecimento público. Ainda segundo Sant'Anna \& Azevedo (2000), 0 controle da água destinada ao abastecimento é feito colocando-se al gicidas, como sulfato de cobre ou peróxido de hidrogênio nas represas. Contudo, a aplicação desses produtos pode ge rar efeitos adversos, uma vez que podem ser tóxicos para organismos não-alvo e a própria morte das algas, por lise celular, pode liberar toxinas em concentração suficiente para causar danos à outras espécies e comprometer o uso da água.

Dentre os principais al gicidas utilizados em vários países, destacam-se: os compostos à base de cobre, como sulfato de cobre e os cobres quelados (CRCW QT, 2002; Garling, 1999; Zagatto et al., 1998; Sant Anna \& Azevedo, 2000; Vandiver Jr., 2002); além do peróxido de hidrogênio (Zagatto et al., 1998; Sant'Anna \& Azevedo, 2000), endotal (Garling, 1999; Vandiver Jr., 2002), simazina (CRCWQT, 2002) e diquat (Vandiver Jr., 2002).

Cabe ressaltar que, por se tratarem de substâncias com ação biocida, os algicidas são caracterizados pela legislação brasileira como agrotóxicos e afins e, desse modo, estão sujeitos às mesmas exigências requeridas para este grupo de produtos. Todavia, no Brasil, nenhum al gicida utilizado para tratamento de piscinas, tem uso autorizado para ambientes hídricos (Brasil, 1989; Anvisa, 2003).

\section{Controle de plantas aquáticas}

As plantas aquáticas são vegetais que se desenvolvem em ambientes, temporária ou permanentemente alagados e caracterizam-se pela alta taxa de crescimento e pela capacidade de reprodução assexuada.

0 crescimento excessivo de plantas aquáticas tem prejudicado o uso múltiplo dos recursos hídricos no Brasil e em vários outros países. Em geral, tal desequilíbrio é gerado por efeito da ação antrópica sobre o meio ambiente. Os principais fatores responsáveis por esse crescimento são: excesso de nutrientes (eutro- fização do ecossistema), desequilíbrio na cadeia de inimigos naturais, alteração do regime hídrico e introdução de espécies exóticas.

0 controle de plantas aquáticas deve ser realizado quando as mesmas apresentam crescimento desequilibrado nos ambientes, prejudicando várias atividades, tais como a navegação, a captação de água para irrigação e uso público; a pesca, o lazer, os esportes náuticos, 0 funcionamento de unidades de geração de energia elétrica; ou favorecendo a proliferação de organismos vetores de doenças e ameaçando a diversidade biológica dos ecossistemas, ou seja, comprometendo assim a saúde pública, 0 meio ambiente e a utilização da água para diversos fins. Dentre os métodos de controle destacam-se: 1) o controle mecânico, realizado por meio de colheitas mecânicas ou manuais, queimadas, sombreamento, alteração do nível da coluna d'água, corantes que limitam a penetração de luz, entre outros; 2) o controle biológi$\mathrm{co}$, alcançado por meio de manejo de predadores ou parasitas (peixes, fungos, insetos, bactérias); e 3) o controle químico, realizado por meio de herbicidas sistêmicos ou de contato, seletivos ou de largo espectro de absorção (I bama, 2001).

Entre os principais ingredientes ativos herbicidas utilizados em vários países do mundo para o controle de plantas aquáticas destacamse: 2,4-D, diquat, endotal, fluridone, glifosato e imazapir. Segundo a Anvisa (2003), apenas o ingrediente ativo fluridone tem autorização de uso para este fim no Brasil, sendo justamente o único não utilizado na agricultura.

\section{Controle de vetores em campanhas de saúde pública}

U ma das principais estratégias dos programas de controle das doenças transmitidas por vetores tem sido o combate direto aos mesmos, tendo em vista a indisponibilidade de vacinas ou drogas efetivas para a prevenção ou tratamento dessas doenças. 0 objetivo dos programas de saúde pública é erradicar o transmissor ou manter a transmissão em níveis que possam ser tratados pelos serviços de saúde sem a necessidade de medidas adicionais de controle (Hayes, 1991; WHO, 1997).

Segundo levantamentos realizados na Coordenação Geral de Insumos Estratégicos (CGIES), da Fundação Nacional de Saúde (Funasa), os programas de saúde pública que utilizam agrotóxicos aplicados diretamentena água para com- 
bate de determinada fase do ciclo de vida dos vetores são: malária (Bacillus sphaericus), dengue (temephós, methoprene, Bacillus thuringiensis) e esquistossomose (niclosamida). De um modo geral, os métodos de controle de vetores estão baseados no manejo ambiental (ex. saneamento, alterações físicas do ambiente), e nos controles biológico (e.g. predadores naturais, armadilhas com feromônios, agentes microbiológicos) e químico (agrotóxicos).

\section{Bases legais pertinentes}

\section{Legislação relacionada à qualidade de água}

Quanto à poluição dos corpos hídricos, a lei no 9.605, de 12.02.98 (Lei de Crimes Ambientais), dispõe sobre as sanções penais e administrativas derivadas de conduta e atividades lesivas ao meio ambiente. Seu artigo 33 determina pena de detenção ou multa para quem provocar, pela emissão de efluentes ou carreamento de materiais, o perecimento de espécimes da fauna aquática existentes em rios, lagos, açudes, lagoas, baías ou águas jurisdicionais brasileiras, incorrendo das mesmas penas aquele que, segundo 0 artigo 54, causar poluição de qualquer natureza em níveis tais que resultem ou possam resultar em danos à saúde humana, ou que provoquem a mortandade de animais ou a destruição significativa da flora.

$\mathrm{N}$ o que diz respeito ao controle das atividades utilizadoras de recursos ambientais consideradas efetivamente ou potencialmente poluidoras, bem como capazes de causar degradação ambiental, a resolução do Conselho $\mathrm{Na-}$ cional de M eio Ambiente (Conama) no 237, de 19.12.97, estabelece a necessidade de prévio licenciamento ambiental do órgão ambiental competente, sem prejuízo de outras licenças legalmente exigíveis. No âmbito desta resolução destacam-se as atividades de manejo de recursos aquáticos vivos. Além disso, sobre os parâmetros de qualidade de água, a resolução Conama no 20, de 18.06.86, estabelece os critérios para a classificação das águas doces, salobras e sal inas e a portaria Funasa no 1.469, de 29.12.00, estabelece os parâmetros relativos à qualidade da água para consumo humano e seu padrão de potabilidade.

\section{Legislação relacionada ao uso de drogas veterinárias}

0 decreto-lei no 467, de 13.02.69, define produto de uso veterinário como todos os preparados de fórmula simples ou complexa, de natureza química, farmacêutica, biológica ou mista, com propriedades definidas e destinadas a prevenir, diagnosticar ou curar doenças dos animais, ou que possam contribuir para a manutenção da higiene animal. Além disso, estabelece os critérios para fiscal ização, fracionamento, comercialização, armazenamento, manipulação, acondicionamento e utilização desses produtos, e obriga os estabel ecimentos que desenvolvem essas atividades a se licenciarem no Ministério da Agricultura.

0 decreto № 1.662 , de 6.10.95, que regulamenta a legislação sobre a fabricação e a comercialização de produtos veterinários, define produto veterinário como toda substância química, biológica, biotecnológica ou preparação manufaturada, cuja administração seja aplicada de forma individual ou coletiva, direta ou misturada com os alimentos, destinada à prevenção, ao diagnóstico, à cura ou ao tratamento das doenças dos animais, incluindo os aditivos, suprimentos, promotores, melhoradores da produção animal, anti-sépticos, desinfetantes de uso ambiental ou equipamentos, pesticidas e todos produtos que, utilizados nos animais e/ ou no "habitat", protejam, restaurem ou modifiquem suas funções orgânicas e fisiológicas. Compreendem-se ainda, nesta definição os produtos destinados ao embelezamento dos animais. Além disso, estabelece normas para o registro de tais produtos no $\mathrm{De}$ partamento de Defesa Animal, do M inistério da Agricultura. Cabe ressaltar que 0 artigo 26 estabelece que os produtos de uso veterinário deverão atender às normas de qualidade e segurança para a saúde animal, saúde pública e 0 meio ambiente; e que nos dizeres de rótulo e bula devem estar discriminados, dentre outras coisas, a dose recomendada por espécie.

Várias publicações posteriores normatizam esse decreto. A portaria no 301, de 19.04.96, do M inistério da Agricultura, do Abastecimento e da Reforma Agrária (M AARA), define normas complementares do regulamento de fiscalização de produtos veterinários e estabelecimentos que os fabriquem e ou comercializem. 0 artigo 30 estabelece que os produtos veterinários somente poderão ser comercializados, em qualquer parte do território nacional, depois de devidamente registrados no Departamento 
de D efesa Animal (DAA) e deverão obedecer a uma das seguintes classificações quanto à necessidade de receita para venda: com receita oficial arquivada, com receita veterinária arquivada, com receita veterinária e de venda livre. A portaria no 74, de 11.06.96, da Secretaria de Defesa Agropecuária (SDA), estabelece o roteiro para registro de produtos farmacêuticos de uso veterinário. Para tal registro são exigidas informações quanto a: intoxicação no homem (tratamento, antídoto e dados de centros toxicológicos), efeitos biológicos não desejados (carcinogenicidade, teratogenicidade, mutagenicidade, etc), controle sobre resíduos medicamentosos (Ingesta Diária Admissível - IDA, Limite M áximo de Resíduos - LM Rs), tempo que deve transcorrer entre o último dia de tratamento e 0 abate dos animais para consumo humano, etc. A portaria no 48, de 12.05.97, da SDA, regulamenta o licenciamento e/ ou renovação de licença de produtos antiparasitários de uso veterinário, definindo critérios a serem obedecidos nos testes de eficácia dos produtos com a especificação da espécie animal utilizada no experimento. A portaria no 193, de 12.05.98, do M AARA, regulamenta o licenciamento e a renovação de licença de antimicrobianos de uso veterinário, com a ressal va que o produto deve discriminar a dose recomendada para cada espécie de animal indicada. N enhuma dessas normas prevê a utilização de tais produtos em ambientes hídricos. Curiosamente a instrução normativa no 42, de 20.12.99, da SDA, que altera o Plano $\mathrm{N}$ acional de Controle de Resíduos em Produtos de Origem Animal, inclusive o pescado, cita como antibióticos mais recomendados na piscicultura, a tetraciclina, a eritromicina e a oxitetraciclina.

\section{Legislação comum relacionada ao uso de produtos algicidas, herbicidas e para controle de vetores}

A lei no 7.802 , de 11.07.89, dispõe sobre a pesquisa, a experimentação, a produção, a embalagem e rotulagem, 0 transporte, 0 armazenamento, a comercialização, a propaganda comercial, a utilização, a importação, a exportação, o destino final dos resíduos e embalagens, o registro, a classificação, o controle, a inspeção e a fiscalização de agrotóxicos, seus componentes e afins. Esta lei ainda define agrotóxicos e afins como os produtos e os agentes de processos físicos, químicos ou biológicos, destinados ao uso nos setores de produção, no armazena- mento e beneficiamento de produtos agrícolas, nas pastagens, na proteção de florestas, nativas ou implantadas, e de outros ecossistemas e também de ambientes urbanos, hídricos e industriais, cuja final idade seja alterar a composição da flora ou da fauna, a fim de preserválas da ação danosa de seres vivos considerados nocivos. 0 decreto no 4.074, de 8.01.02, regulamenta essa lei e estabelece as competências dos M inistérios da Agricultura, Pecuária e Abastecimento (MAPA), da Saúde (MS) e do M eio Ambiente (M M A). Além disso, a publicação desse decreto abriu caminho para várias normatizações complementares a serem definidas, incluindo produtos microbiológicos, produtos destinados exclusivamente aos ambientes hídricos e os produtos agrotóxicos/domissanitários registrados conforme a lei no 6.360 , de 23.09.76.

Essa lei e decreto são complementados por normas que dispõem sobre pesquisa e experimentação (portaria da Secretaria de Vigilância Sanitária - SVS no 14, de 24.01.92), o registro de produtos químicos (portaria da SVS no 03, de 16.01.92, portaria I bama no 84, de 15.10.96) e de produtos microbiológicos (portaria Ibama no 131, de 3.11.97, resolução da Agência N acional de Vigilância Sanitária - Anvisa, no 194, de 8.07.02). Ressalta-se que a portaria SVS no 03/92 estabelece a monografia técnica dos produtos agrotóxicos, documento este que dá publicidade ao deferimento de um ingrediente ativo na vigilância sanitária, e define sua autorização de uso para os vários tipos de ambiente, além do estabelecimento de doses e culturas. Segundo a Anvisa (2003), no Brasil não há produtos registrados para o controle de algas em reservatórios.

\section{Legislação relacionada aos produtos utilizados no controle de vetores}

A lei no 6.360 , de 23.09.76, dispõe sobre a vigilância sanitária a que ficam sujeitos os medicamentos, as drogas, os insumos farmacêuticos e correlatos, cosméticos, saneantes e outros produtos. Os produtos utilizados no controle de vetores são regulamentados nessa lei, por serem considerados inseticidas domissanitários. $N$ esse contexto, define-se inseticida aquele saneante domissanitário destinado ao combate, à prevenção e ao controle dos insetos em habitações, recintos e lugares de uso público e suas cercanias. Essa lei é regulamentada pelo decreto ํo 79.094, de 5.01.77, que dispõe sobre a vigi- 
lância sanitária a que ficam sujeitos os insumos farmacêuticos e correlatos, saneantes e outros produtos. A lei no 10.191, de 14.02.01 dispõe sobre a aquisição de produtos para a implementação das ações de saúde no âmbito do M inistério da Saúde. Esta lei estabelece que a aquisição de inseticidas para a implementação de ações de saúde poderá ser realizada por intermédio de organismos multilaterais internacionais de que o Brasil faça partee, neste caso, obedecerão aos procedimentos por eles adotados.

A portaria do M inistério da Agricultura no 329, de 2.09.85, proibiu a comercialização, 0 uso e a distribuição dos produtos agrotóxicos organoclorados, com exceção dos aplicados pelos órgãos públicos competentes, em campanhas de saúde pública de combate a vetores de agentes etiológicos de moléstias. Todavia, a proibição definitiva de uso do DDT em saúde pública ocorreu somente em 1998 com a publicação da portaria no 11, de 8.01.98.

Com relação aos produtos domissanitários, a portaria da Secretaria Nacional de Vigilância Sanitária (SN VS) no 321, de 28.07.97, aprova normas gerais para produtos inseticidas e outros produtos desinfestantes destinados à venda direta ao consumidor e para aplicação por entidades especializadas. Ainda sobre a mesma matéria, destacam-se as portarias: no 631 SNVS, de 10.12.97, no 380 SVS, de 26.04.99 ea Resolução Anvisa-RDC no 184, de 22.10.01.

\section{Considerações finais}

Por meio da identificação das demandas para o uso de drogas veterinárias, agrotóxicos e afins, verificou-se a importância de tais produtos no controle de determinados organismos em ambientes hídricos, uma vez que muitos desses organismos trazem grandes prejuízos à economia, à saúde humana e ao meio ambiente.

Diferentes métodos podem ser utilizados para controlar organismos aquáticos ou que tenham seu ciclo de vida associado a água, com destaque para os controles químico e biológico. 0 controle químico utilizado refere-se principalmente ao uso de substâncias químicas no combate a esses organismos. Esse método vem sendo muito discutido nos últimos anos, nos países onde é utilizado com maior experiência, já que muitos dos produtos promovem a seleção biológica dos organismos indesejáveis, que adquirem resistência às substâncias químicas. Outro ponto desfavorável à adoção do controle químico é a agressão, muitas vezes irreversível, que estes produtos podem provocar no meio ambiente, o que acaba gerando protestos de toda a sociedade.

Q uanto à utilização de drogas veterinárias diretamente em ambientes hídricos, observa-se que o decreto no 1.662/95 estabelece que todo produto veterinário deverá ser registrado no Departamento de D efesa Animal da Secretaria de Defesa Agropecuária, do MAARA, atualmente M inistério da Agricultura, Pecuária e Abastecimento (M APA). 0 requerimento para registro de produtos veterinários deverá ser acompanhado de relatório técnico descritivo, incluindo informações sobre os testes de controle da toxicidade, com indicativo das margens entre os níveis de uso e o aparecimento de sintomas tóxicos na espécie mais sensível, ou buscando a correlação com animais controles, ou com outros métodos cientificamente reconhecidos. Ressalta-se que para os casos de uso de drogas em aqüicultura/piscicultura, não há legislação específica e tampouco produtos com registro para este fim. Além disso, diferentemente dos agrotóxicos e afins, tais produtos hoje no Brasil, são avaliados apenas pelo órgão registrante, O MAPA, sem nenhum envolvimento dos setores de saúde e meio ambiente. Esse fato é preocupante, pois na medida em que não existe nenhuma avaliação do perigo que essas drogas representam para as comunidades aquáticas, para o consumidor dessa água e, consequentemente, para o consumidor de alimentos da área tratada, a extensão dos riscos desse tipo de uso, à saúde humana e ao meio ambiente, é ainda desconhecida. Essa consideração reflete uma situação explicitada por Benbrook (2002) para os Estados Unidos. Nesse contexto, 0 autor comenta que a fal ta de produtos regulamentados para este fim aumenta o potencial para abusos e usos incorretos, levando os criadores a utilizarem drogas ilegais, em geral aprovadas para outros usos. Assim tornase difícil estabelecer o quantitativo do uso de drogas em ambientes hídricos e dos perigos potenciais, pois há falta de dados e as leis são fragmentadas.

Q uanto à utilização de al gicidas e herbicidas em ambientes hídricos, observa-se que a necessidade do uso desses produtos é gerada, principalmente, pelo enriquecimento dos ambientes com nutrientes, tais como os oriundos do lançamento de esgotos domésticos. Desse modo, a simples melhoria das políticas públicas de saneamento, valorizando e investindo na 
construção de estações de tratamento de esgotos e de efluentes industriais poderia minimizar tais demandas.

Os produtos aplicados em ambientes hídricos para controle de plantas aquáticas (herbicidas) têm dois modos de ação - contato e sistêmico. No primeiro, a dose aplicada é estabelecida por área de superfície d'água; e no segundo, a dose é calculada por volume de água. Os produtos cujas doses são expressas em g/ha (massa/área) dificultam a determinação da concentração da exposição dos organismos aquáticos. $N$ esses casos, a exposição pode ser super ou subestimada, na dependência de uma série de fatores ambientais (fluxo d'água, ventos, cobertura vegetal) e técnicos (tamanho da gota, fluxo da aspersão, presença de adjuvantes). A concentração dos produtos na coluna d'água pode, todavia, ser estimada por meio da proposição de um cenário com condições extremas - pior caso e modelos de dispersão. Em todos os casos, o monitoramento ambiental torna-se fundamental para validar as hipóteses propostas.

Quanto à utilização de produtos no controle de vetores, verifica-se que os inseticidas utilizados em campanhas de saúde pública são registrados no país pela Anvisa, com base em dados de eficiência e toxicidade. Todavia, conforme a lei no 7.802/89 e o decreto no 4.074/02, os produtos a serem utilizados em ambientes hídricos deveriam ser registrados no Ibama, mediante anuência da Anvisa. Desse modo, de acordo com a legislação pertinente, os produtos utilizados em campanhas de saúde pública, aplicados em ambientes hídricos deveriam ser registrados mediante a avaliação da Anvisa e do I bama, o que ainda não ocorre no Brasil. Além disso, a opção pela estratégia de controle, seja por meio da utilização de inseticidas químicos ou biológicos, ou ações sanitárias e de saúde ambiental é avaliada pela Funasa, tomando por base indicadores epidemiológicos e recomendações da Organização Mundial de Saúde (OMS).

Do ponto de vista epidemiológico, é difícil correlacionar os efeitos de compostos químicos específicos sobre a saúde humana. As dificuldades são inúmeras em face da variedade dos métodos de utilização dos produtos, a multiplicidade de fatores de risco no ambiente e no estilo de vida, a dificuldade de mensurar com precisão os níveis e tempo de exposição aos contaminantes, e o desconhecimento da toxicidade apresentada por misturas de substâncias.
Existem poucos estudos sobre o comportamento ambiental dos agrotóxicos e afins em climas tropicais. As propriedades físico-químicas e toxicológicas diferem grandemente entre os compostos de diferentes classes químicas e, inclusive, para os de uma mesma classe química, 0 que torna extremamente difícil a tarefa de fazer generalizações sobre os destinos e impactos dos mesmos no ambiente (Dores \& De-LamonicaFreire, 2001). 0 mesmo pode ser afirmado com relação à presença de drogas veterinárias e resíduos de medicamentos humanos em ambientes hídricos, fato que tem gerado muita preocupação na comunidade científica, principalmente em países da Europa (Jones et al., 2003).

Embora algumas vezes utilizados de acordo com as recomendações prescritas em seus registros, não se exclui a possibilidade de que concentrações mais el evadas dos produtos venham a ocorrer, seja devido a erros de dose na aplicação, mudanças no fluxo hídrico esperado, inversão climática, ou mesmo, devido ao acúmulo da aplicação de diversas doses de produtos persistentes. Não existe nível seguro previsível para agrotóxicos na água quando pode ocorrer inclusive, o fenômeno da biomagnificação (Eichelberger \& Lichtenberg, 1971).

0 arcabouço legal que disciplina o registro, a pesquisa, a importação, o controle e o uso dos produtos de utilização médico-sanitário, em campanhas de saúde pública, éainda deficiente no País, uma vez que, os procedimentos para pleitos de registro, dados necessários para as avaliações de eficiência e ecotoxicológica, assim como os procedimentos referentes ao descarte de embalagens e fiscalização de uso não estão contempladas na legislação.

0 decreto no 4.074/02 não traz regras específicas para produtos a serem utilizados em ambientes hídricos e isto pode se tornar um problema, na medida em que, com a ausência de uma regulamentação específica para a avaliação do uso de produtos dessa natureza, nesses ambientes, a segurança do ecossistema pode ser seriamente comprometida.

A portaria Funasa no 1.469/00 estabelece os parâmetros rel ativos à quali idade da água para consumo humano, e a Resolução Conama no 20/86 estabelece os limites máximos de resíduos em água, segundo os seus usos de destino, com os objetivos de preservar a saúde humana e os organismos aquáticos, respectivamente. Essas normatizações, no entanto, não contemplam a maioria dos ingredientes ativos citados neste trabalho, tampouco a maioria dos agro- 
tóxicos utilizados na agricultura que podem vir a contaminar os recursos hídricos.

É importante enfatizar que existe, ainda hoje, muita controvérsia com relação aos efeitos tóxicos crônicos dos agrotóxicos, e outras substâncias, para o ser humano, principalmente quando consumidos em baixas doses ao longo de toda uma vida (Dores \& De-LamonicaFreire, 2001). A mesma controvérsia aplica-se ao desconhecimento dos efeitos tóxicos crônicos dessas substâncias sobre os organismos aquáticos.

Todos os pontos abordados neste trabal ho direcionam para a necessidade de se desenvolver estudos sobre a presença de resíduos de agrotóxicos e afins, bem como de drogas veterinárias, em ambientes hídricos, e sobre seus efeitos na biodiversidade aquática e na saúde humana em condições tropicais. Observou-se também a necessidade premente do debate entre todos os órgãos en volvidos na liberação e no uso dessas substâncias, visando à elaboração de uma legislação integrada e intersetorial, determinando, entre outras coisas, o registro para tal finalidade, os intervalos de segurança, os limites máximos de resíduos em água e os responsáveis pelo uso e pela possível ocorrência de danos à saúde e ao meio ambiente. Em todo o caso, deve-se primar pelo diálogo, objetivando atender aos interesses de todos os envolvidos, incluindo: produtores, usuários e sobretudo, membros das comunidades que dependem desses ambientes para a manutenção da sua sobrevivência e nesse caso devem conhecer e deliberar sobre o potencial de risco a que estarão submetidos.

\section{Colaboradores}

AA M aximiano trabalhou na concepção teórica, formatação do trabalho, pesquisa bibliográfica ena análise do material coletado; RO Fernandes, na formatação do trabalho, pesquisa bibliográfica e na análise do material; FP Nunes, na formatação do trabalho, realização de pesquisa bibliográfica e na análise do material; M P Assis, na formatação do trabalho, realização de pesquisa bibliográfica e entrevistas e na análise do material. RV M atos e CGS trabalharam no levantamento bibliográfico e na análise do material; e EC Oliveira Filho, na concepção teórica, orientação do trabalho, análise do material e na revisão do conjunto da obra. 


\section{Referências bibliográficas}

Anvisa (Agência N acional de Vigilância Sanitária) 2003. Toxicologia - monografias de produtos agrotóxicos. 22 maio 2003. Disponível em <http://www.anvisa.gov. $\mathrm{br} /$ toxicologia/monografias/index.htm>.

Benbrook CM 2002. Antibiotic drug use in U.S. aquaculture. 15 maio 2003. Disponível em <http://www.iatp. org/fish/library/uploadedFiles/Antibiotic_Drug_Use in_US_Aquaculture.doc.>

Brasil 1989. Lei no 7.802, de 11 de julho de 1989. Dispõe sobre ... agrotóxicos, seus componentes e afins e dá outras providências. 15 maio 2003. Disponível em <http://www.presidencia.gov.br/ccivil_03/Leis/ L7802.htm>

Buss DF 2002. Proteção à vida aquática, participação das comunidades e políticas de recursos hídricos. Ciência $\&$ Ambiente 25:71-84

CRCW QT (Cooperative Research Centre for Water Quality and Treatment) 2002. U sing algicides for the control of algae in Australia. 15 maio 2003. Disponível em $<$ http://www.waterquality.crc.org.au/Publictn/algicides_crc.pdf>

Dores EFG \& De-Lamonica-Freire EM 2001. Contaminação do ambiente aquático por pesticidas. Estudo de caso: Águas usadas para consumo humano em Primavera do Leste, M ato Grosso - Análise preliminar. Química N ova 24(1):27-36.

Eichelberger JW \& LichtenbergJJ 1971. Persistence of pesticides in river water. Environmental Science and Technology, 5(6):541-544.

Garling DL 1999. Nuisance aquatic plant control using algicides and herbicides. 15 maio 2003. Disponível em <http://www.msue.msu.edu/oakland/aquatics2.html>

Hayes Jr. WJ 1991. Introduction, pp. 1-38. In WJ Hayes Jr. \& ER Laws Jr. (orgs.). H andbook of pesticide toxicology. Academic Press, San Diego.

I bama (Instituto Brasileiro do M eio Ambiente e dos Recursos N aturais Renováveis) 2001. Controle de plantas aquáticas por meio de agrotóxicos e afins. DILIQ/ Ibama, Brasília.
Jones OAH, Voulvoulis N \& Lester JN 2003. Potential impact of pharmaceuticals on environmental health. Bulletin of the W orld H ealth Organization 81(10):768769.

M aciel Jr. AA et al. 2000. Interfaces da gestão de recursos hídricos e saúde pública, pp. 396-420. In HR M uñoz (org.). Interfaces da gestão de recursos hídricos. Desafios da lei de águas de 1997. Secretria de Recursos Hídricos, Brasília.

Queiroz JF, Lourenço JNP \& Kitamura PC 2002. A Embrapa e a aqüicultura: demandas e prioridades de pesquisa. Embrapa Informação Tecnológica. (Texto para Discussão; 11), Brasília. Disponível em <http://www22. sede.embrapa.br/unidades/uc/sge/textoll.pdf>

Sant'Anna CL \& Azevedo M TP 2000. U ma ameaça à qualidade da água. Espalhadas pelo Brasil. Pesquisa Fapesp 53:28-30.

Vandiver Jr. VV 2002. Biology and control of algae. University of Florida. 15 maio 2003. Disponível em <http:// edis.ifas.ufl.edu/BODY_AG142>

WHO (World Health Organization) 1997. Vector control. $M$ ethods for use by individuals and communities. W orld H ealth Organization, Genebra.

Zagatto PA, Aragão MA, Domingues DF, Buratini SV \& Araújo RPA 1998. Avaliação ecotoxicológica do reservatório do Guarapiranga, SP, com ênfase à problemática das algas tóxicas e al gicidas. Anais do IV Congresso Latino-Americano deFicologia, 1:63-81.

Zampieron SLM \& VieiraJLA 2003. Poluição da água. M aterial de apoio - Textos. 20 maio 2003. Dissponível em <http://educar.sc.usp.br/biologia/textos/m_a_txt5. html>

Zaniboni Filho E 1997. 0 desenvolvimento da piscicultura brasileira sem a deterioração da qualidade da água. Revista Brasileira de Biologia 57(1):2-9.

Artigo apresentado em 20/07/2004

Aprovado em 9/08/2004

Versão final apresentada em 9/09/2004 